\title{
Australian scorpion stings: a prospective study of definite stings
}

\author{
Geoffrey K. Isbister ${ }^{\mathrm{a}, \mathrm{b}, *}$, Erich S. Volschenk ${ }^{\mathrm{c}, \mathrm{d}}$, Corrine R. Balit ${ }^{\mathrm{b}}$, \\ Mark S. Harvey ${ }^{\mathrm{d}}$ \\ ${ }^{a}$ Discipline of Clinical Pharmacology, University of Newcastle, Newcastle, NSW, Australia \\ ${ }^{\mathrm{b}}$ NSW Poisons Information Centre, The Children's Hospital, Sydney, NSW, Australia \\ ${ }^{\mathrm{c}}$ School of Environmental Biology, Curtin University of Technology, Bentley, WA, Australia \\ ${ }^{\mathrm{d}}$ Department of Terrestrial Invertebrates, Western Australian Museum, Perth, WA, Australia
}

Received 14 January 2003; accepted 26 February 2003

\begin{abstract}
There is little information on scorpion stings in Australia. The aim of this study is to describe the circumstances and clinical effects of stings by Australian scorpions. Cases of scorpion stings were collected prospectively from calls and presentations to Australian poison information centres and emergency departments from February 2000 to April 2002. Only definite scorpion stings where the scorpion was immediately collected and expertly identified were included. There were 95 patients, 33 males and 62 females, with a mean age of 32 (SD 19.5; range 1-71) and 23 children (age $<15$ years). Three families of scorpions caused all stings: Buthidae (79), Bothruiridae (11, all Cercophonius spp.) and Urodacidae (five, all Urodacus spp.). The majority of stings (76\%) were by one genus of scorpion Lychas spp. Seventy one percent of stings occurred between 6pm and $8 \mathrm{am}$ and $82(86 \%)$ occurred indoors. Sixty percent of stings occurred on distal limbs. The median duration of effects was $6 \mathrm{~h}$ (interquartile range (IQR): $1-24 \mathrm{~h}$ ). Immediate localised pain occurred in all cases and was severe in 76 cases $(80 \%)$. Other local effects included red mark/redness (66\%), tenderness (35\%), numbness (12\%) and paraesthesia (11\%). Minor systemic effects (nausea, headache and malaise) occurred in $11 \%$ of cases. There were no deaths or major systemic envenoming. Less severe effects were observed for the larger Urodacus species, compared to Lychas spp. Scorpion stings in Australia do not appear to cause severe or life-threatening effects, even in children. This differs from other parts of the world, where severe envenoming is reported. The major clinical effect is severe pain, consistent with other scorpion stings. Most stings occurred indoors and at night.
\end{abstract}

(C) 2003 Elsevier Science Ltd. All rights reserved.

Keywords: Australian scorpion stings; Urodacus; Arachnidism; Lychas; Cercophonius; Envenoming; Pain

\section{Introduction}

Like many parts of the world, Australia is host to a number of families of scorpions (Southcott, 1976). Most

\footnotetext{
* Corresponding author. Present address: Discipline of Clinical Pharmacology, University of Newcastle, Newcastle Mater Misericordiae Hospital, Clinical Sciences Building, Level 5 Edith Street, Waratah, NSW 2298, Australia. Tel.: +61-2-49-211-293; fax: +61-2-49-602-088.

E-mail address: gsbite@bigpond.com (G.K. Isbister).
}

scorpions are nocturnally active and hide in leaf litter, rocks or burrows during the day. The Australian scorpion fauna consists of over 40 named species in four families, but numerous unnamed species are known and 150-200 species is a more realistic estimate of Australia's scorpion diversity (Volschenk, unpublished data). Scorpions can be locally abundant in Australia, but human contact with these creatures is rare (Southcott, 1976), and is the likely reason that effects of Australian scorpions are not well characterised. Outside of Australia, scorpions are a considerable public health problem affecting large numbers of humans 
each year (Bergman, 1997; Freire-Maia et al., 1994; Ismail, 1994; Groshong, 1993; Ghalim et al., 2000; Abroug et al., 1999; Dehesa-Davila and Possani, 1994). Medically significant scorpion stings are almost universally characterised by intense local pain, usually without local tissue injury. Systemic effects occur in a smaller proportion of scorpion stings, depending on scorpion species involved and are caused by a variety of excitatory neurotoxins (Luca and Meier, 1995).

There is little information on scorpion stings in Australia, and reviews have collected together about a dozen cases of stings reported over the last 150 years (Southcott, 1976; Sutherland and Tibballs, 2001; Southcott, 1986). Southcott reviewed cases from the early 19th century through to the first half of this century (Southcott, 1976). His review included two published deaths in Victoria (MacGillivray, 1866b; MacGillivray, 1866a) and one report of a death of a baby in Western Australia (Southcott, 1976). The former two were discounted by Southcott in 1973 and in the latter case, the scorpion was not retrieved (Southcott, 1976). Flecker was the first to report stings by formally identified scorpions in 1937(Flecker, 1937) with four stings from the smaller buthid scorpions, and one from a species Urodacus. Southcott adds a few further cases in his review (Southcott, 1976) and there have been no subsequent reports.

Most experts agree that Australia's scorpions pose little threat to people, but the evidence is not available to support or refute this. We present a prospective series of scorpion stings that were recruited Australia-wide. In each case of definite sting the scorpion was obtained and then expertly identified to genus or species level.

\section{Methods}

The methodology has been described in detail elsewhere (Isbister, 2002b). Subjects were recruited prospectively over a 27 month period from February 2000 to April 2002 from calls and presentations to Royal Darwin Hospital (RDH), and calls to New South Wales (NSW) and Western Australia (WA) Poison Information Centres (PICs). Subjects were contacted within $24 \mathrm{~h}$ of the sting and followed up after 1-2 weeks. For inclusion as a definite sting there needed to be a clear history of the scorpion sting and collection of the scorpion at the time of the sting.

The following information was recorded for each scorpion sting: demographics (age, gender, geographical location), circumstances of the sting (location, time, date, activity at the time), sting site, local and systemic effects (onset, duration, severity), and past medical history (full details available from the authors). Duration of effects was defined as the length of clinical effects of the sting but not the presence of a mark alone. Severe pain was defined as pain greater than that of a bee sting or equivalent.
All identifications were done by an expert arachnologist (ESV or MH) and the taxonomy follows that of Kovarík and Koch (Kovarik, 1997; Koch, 1997). Ethics approval was obtained from the Joint Institutional Ethics Committee of the Royal Darwin Hospital and the Menzies School of Health Research. All statistical analysis was done using GraphPad Instat (Version 3.05, 32 bit for Win 95/NT created September, 2000).

\section{Results}

A total of 192 subjects were recruited during the 27 month period, and of these there were 95 definite scorpion stings. Table 1 lists the family, genera and species of scorpions causing stings. Seventy-two stings were by the small buthid scorpions of the genus Lychas. The majority of stings occurred in the warmer months in the southern hemisphere (Fig. 1) and stings occurred throughout Australia (Fig. 2). Sixty-seven of 94 stings (71\%) occurred at night (6 pm to $8 \mathrm{am})$ and there was no time provided for one sting. Forty-four of $66(67 \%)$ stings that occurred in NSW and WA only were at night, and all stings from the NT occurred at night. Eighty-two (86\%) stings occurred indoors. The circumstances of the sting were: $21 \%$ trod on the scorpion, $16 \%$ picked up the scorpion or an object which the scorpion was on, $15 \%$ were stung in bed and $14 \%$ were dressing at the time and in $35 \%$ other activities.

Of the 95 subjects with definite stings, there were 33 males (35\%) and 62 females (65\%). Age ranged from 1 to 85 years with a median age of 33 years IQR: 14-46 years). There were 23 paediatric cases (ages $<15$ years). Stings occurred to all parts of the body, with $60 \%$ distal (hand or foot), $26 \%$ on the proximal limb, $8 \%$ on the trunk, $4 \%$ on the head/neck and $1 \%$ on multiple regions. The median duration of effects was $6 \mathrm{~h}$ (IQR: 1-24h), although this differed significantly between scorpion families with a much longer

Table 1

Scorpions involved in the study, grouped by family. The commonest genus was Lychas with 72 of the total 95

\begin{tabular}{llr}
\hline Family & Species & No. \\
\hline Buthidae (79) & Lychas marmoreus $^{\mathrm{a}}$ & 62 \\
& Lychas variatus & 4 \\
& Lychas spp. & 6 \\
& Isometrus spp. & 4 \\
& Isometroides spp. $^{*}$ & 2 \\
Bothriuridae & Other & 1 \\
Urodacidae & Cercophonius squama $^{\mathrm{b}}$ & 5 \\
\hline
\end{tabular}

\footnotetext{
${ }^{\text {a }}$ See Fig. 2A.

b See Fig. 2B.

c There were three species of Urodacus scorpions, U. armatus,
} $U$. novaehollandiae and U. planimanus. 


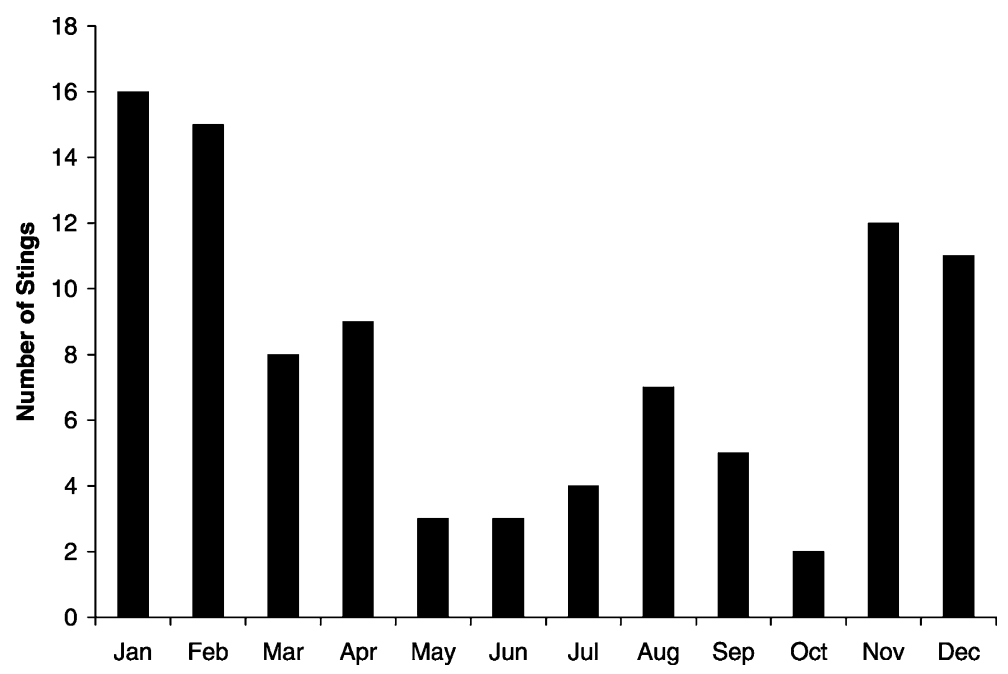

Fig. 1. Seasonal distribution of scorpion stings in Australia. The data for February, March and April were adjusted because they were included three times.

duration for buthid scorpions of $12 \mathrm{~h}$ (IQR: 2-24 h) (Table 2).

Pain occurred in all 95 stings, was mild to moderate in 17 cases $(20 \%)$ and severe or 'very' severe in 76 cases $(80 \%)$, with a median duration of $2 \mathrm{~h}$ (IQR: $1-5.5 \mathrm{~h}$ ). Puncture marks occurred in $27 \%$ of stings. Swelling occurred in $14 \%$ and redness or a red mark in $66 \%$ of cases. Tenderness occurred in $35 \%$ of cases, numbness in $12 \%$ and paraesthesia in $11 \%$. Systemic effects occurred in $11 \%$ of all stings, all minor including nausea, headache and malaise.

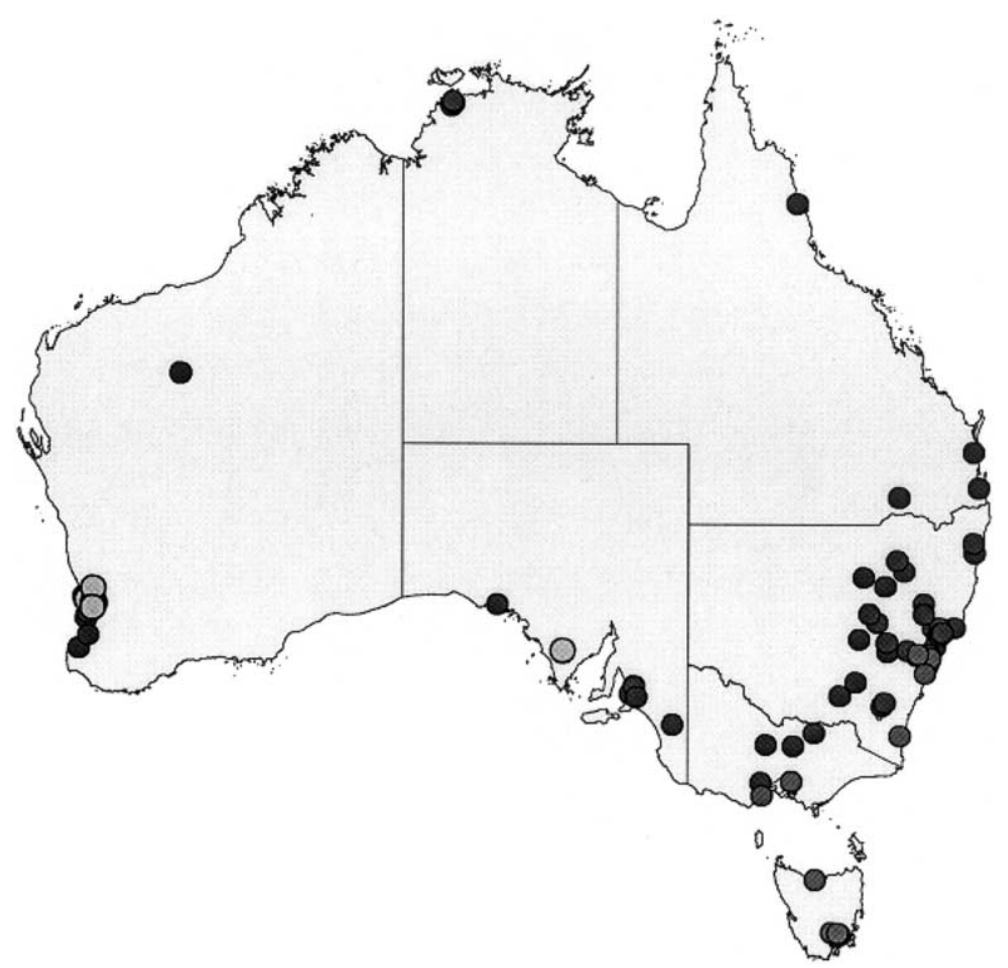

Fig. 2. Geographical distribution of scorpion stings in Australia. The three families are represented by different shaded circles: dark—Buthidae; medium—Bothriuridae; light—Urodacidae. 
Table 2

Clinical effects of scorpions stings by genus

\begin{tabular}{|c|c|c|c|c|c|c|}
\hline Scorpion type & $\begin{array}{l}\text { Puncture } \\
\text { marks }(\%)\end{array}$ & $\begin{array}{l}\text { Severe } \\
\text { pain }(\%)\end{array}$ & $\begin{array}{l}\text { Duration of } \\
\text { pain }(I Q R)^{a, b}\end{array}$ & $\begin{array}{l}\text { Distal limb } \\
\text { stings }(\%)\end{array}$ & $\begin{array}{l}\text { Total duration } \\
\text { of effects (IQR) }\end{array}$ & $\begin{array}{l}\text { Systemic } \\
\text { effects }(\%)\end{array}$ \\
\hline Buthidae & 24 & 89 & $2(1-8)^{\mathrm{b}}$ & 57 & $12(2-24)^{\mathrm{b}}$ & 11 \\
\hline Lychas spp. & 25 & 90 & $2(1-8)$ & 57 & $11(2-24)$ & 13 \\
\hline Isometrus spp. ${ }^{\mathrm{c}}$ & 25 & 50 & - & 50 & - & 0 \\
\hline Isometroides spp. $^{\mathrm{c}}$ & 0 & 100 & - & 50 & - & 0 \\
\hline Bothriuridae C. squama & 54 & 73 & $1(0.75-2)^{b}$ & 73 & $1(0.75-2.5)^{\mathrm{b}}$ & 9 \\
\hline Urodacidae Urodacus spp. ${ }^{\mathrm{c}}$ & 20 & 0 & $0.5(0.4-0.9)^{\mathrm{b}}$ & 80 & $0.5(0.5-2)^{\mathrm{b}}$ & 0 \\
\hline
\end{tabular}

${ }^{\text {a }}$ Duration of pain and effects is given as a median and interquartile range because data were not normally distributed and all are in hours.

b Significant difference between three families $(p<0.01)$.

c Number of cases were small for these groups.

Table 2 gives information on the clinical effects produced by the different families of scorpions. There were no cases of hypersensitivity reactions ( $0 \%$; 95\% CI 0-3.8 \%), despite a history of minor bee allergy in eight patients and bee sting anaphylaxis in one patient.

Five patients attended hospital, five patients saw their local doctor and 85 remained at home. First aid or treatment was applied in 60 of the 95 cases (63\%). The commonest treatment was ice or cold pack in 45 cases $(47 \%)$. Twenty patients took oral analgesia (paracetamol [12], paracetamol/codeine phosphate [4], ibuprofen [1] and unknown [3]). There was complete relief in only one patient, partial improvement in eight of the 20 patients (40\%) and minimal or no effect in the remainder.

In one case a dog was stung immediately after a 4 year old girl was stung. The dog (a small dash hound) suffered similar effects with obvious pain and inability to walk for $2 \mathrm{~h}$.

\section{Discussion}

This study characterises the epidemiology and clinical effects of scorpion stings and provides the first reliable information of the effects of the major groups of scorpions in Australia. It uses a large prospective series of cases where the scorpions were expertly identified to allow correlation between taxonomic group and clinical effects. Australian scorpions appear to cause severe pain for a period of hours, but no major systemic effects.

The analysis was done on 95 definite scorpion stings with expert identification. All cases were followed up for at least 1 week to define clearly the time course of the clinical effects. The study includes a sample that is a good representation of the majority of cases of scorpion sting presenting to health care facilities in Australia. Although a number of biases were introduced in the recruitment of definite cases, Fig. 2 shows that cases were recruited from most parts of Australia, although there were relatively fewer from Queensland.
Scorpion stings appear to be relatively rare in Australia, compared to spider bites and other arthropod reactions, such as bees, wasps and ants, and this is most likely due to the cryptic nature of these animals and their infrequent exposure to people. In a similar prospective study of definite spider bites over a 2 year period, almost eight times as many spider bites were recorded (Isbister and Gray, 2002). In addition, the epidemiology of scorpion stings differs to that of spiders and this may be useful for differentiating scorpion stings from spider bites when the creature is not seen or caught. The majority of scorpion stings (71\%) occurred at night (between $6 \mathrm{pm}$ and $8 \mathrm{am}$ ), which is consistent with the nocturnal habit of these creatures. This compares to spider bites, which are more common during daylight hours. Only a third of spider bites occurred between 8 pm and 8 am (Isbister and Gray, 2002). The reason for the peak for scorpion stings being in the evening is likely to be due to overlap of their activity periods (nocturnal) and the evening activities of people. Scorpion stings also occur more commonly indoors. It is possible that many patients presenting with severe pain from an unknown bite or sting at night, have been stung by a scorpion, although other creatures such as centipedes may cause a painful bite (Southcott, 1986). The difference in circumstances of scorpion stings compared to spider bites is likely to be similar in other parts of the world, but would require similar prospective studies of definite stings with expert identification to confirm this.

The types of scorpions that cause stings vary across Australia (Fig. 2). Stings from only three of the four Australian scorpion families are reported in this study, fewer than with spiders where over 20 families caused bites (although the vast majority were from six families) (Isbister and Gray, 2002). This is likely to reflect the lesser diversity of scorpions in Australia, compared with more than 30 recorded spider families. This is similar to other parts of the world where there is a much smaller range of species of scorpions responsible for stings, particularly species causing 
severe envenoming (Krifi et al., 1998; Wax, 2002; Gibly et al., 1999; Ismail, 1994; Freire-Maia et al., 1994).

The effects of scorpions in Australia differed significantly between families, with the more severe and longer duration of effects occurring with buthids (mainly Lychas spp.), consistent with the fact that most medically important scorpions worldwide belong to this group, including Centruroides spp., Androctonus spp., Buthus spp., Tityus spp. and Leiurus spp. (Krifi et al., 1998; Wax, 2002; Gibly et al., 1999; Ismail, 1994; Freire-Maia et al., 1994). Lychas spp. are small scorpions that occur in most parts of mainland Australia (Koch, 1997) and were mostly of an average length of $20 \mathrm{~mm}$ in this study (Fig. 3(A)). The study shows that stings from this genus occur throughout Australia and cause the most severe effects. Other groups have a more limited distribution. The only species of scorpion in Tasmania is Cercophonius squama (Acosta, 1990) and in this study five of 11 stings by this species were in Tasmania (Fig. 3(B)) and these were the only five stings in that state.

In this study, the largest species belong to the family Urodacidae. This family occurs throughout much of Australia (Koch, 1997) and stings were only reported from WA and SA. Previous reports have included stings mainly

A.

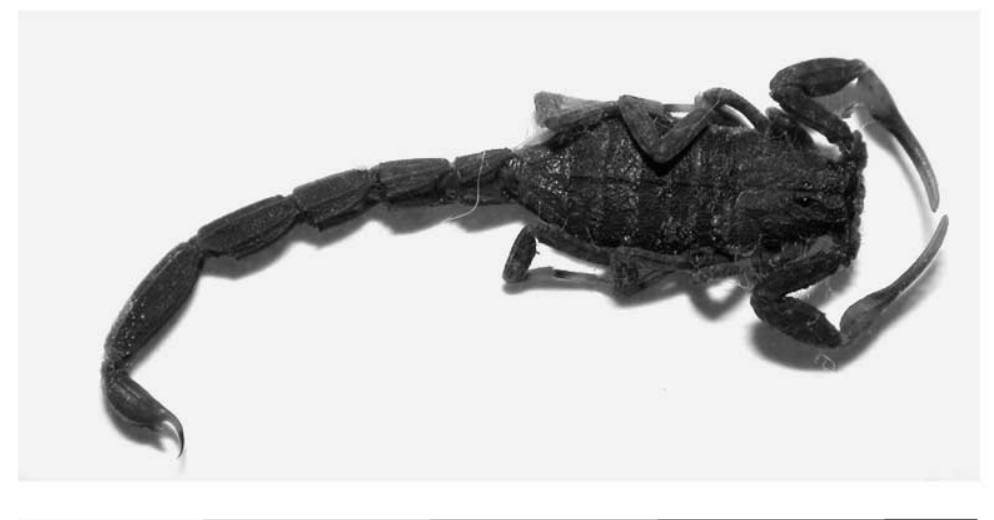

0

$20 \mathrm{~mm}$

B.

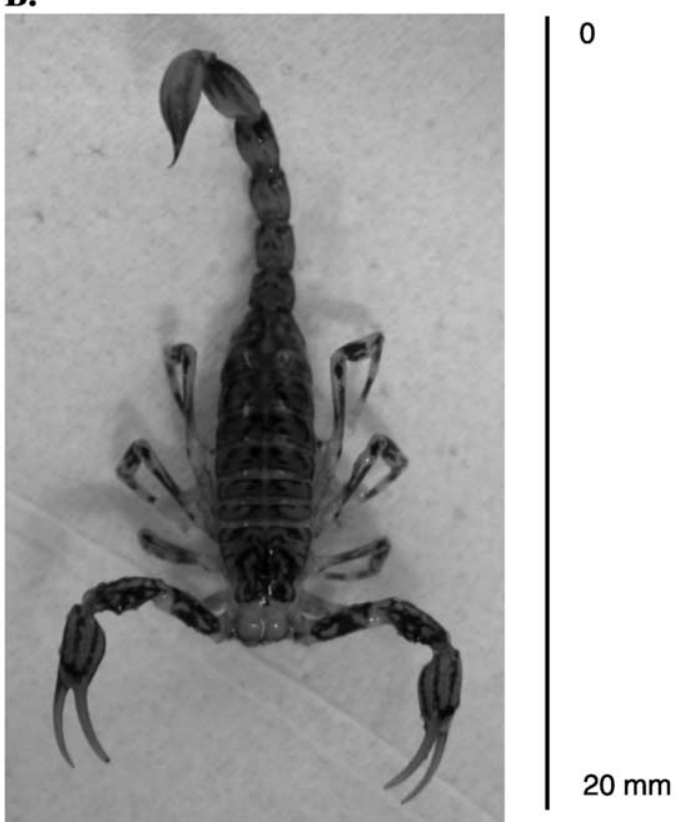

Fig. 3. (A) Lychas marmoreus (Buthidae) from Mount Colah in NSW. (B) Cercophonius squama (Bothriuridae) from Bulli, NSW. 
from SA (Southcott, 1976), but also from Queensland (Flecker, 1937) and WA (Southcott, 1976). Although these scorpions are large, and it has been suggested that the Urodachus spp. are the most important group of Australian scorpions (Sutherland and Tibballs, 2001), they only caused minor effects in the five cases reported here. All five caused only mild to moderate pain, compared to the majority of buthid and bothriurid scorpions stings, which caused severe pain.

Australian scorpions cause relatively minor local effects, and no deaths or patients with major systemic envenoming are reported in this study. In addition, $20 \%$ of the cases were in children who had only minor effects, which again contrasts with most other parts of the world where there is significant paediatric morbidity and mortality (Krifi et al., 1998; Freire-Maia et al., 1994; Ismail, 1994). In US, a country with a similar standard of health care to Australia, scorpion sting is also not a major problem, although in southwest there are large numbers of cases (Wax, 2002; Gibly et al., 1999; LoVecchio et al., 1999). Although the morbidity and mortality, particularly in paediatric patients are worse than Australia, they are not as severe as other parts of the world (Krifi et al., 1998; Ismail, 1994; Freire-Maia et al., 1994).

The study was not specifically aimed to investigate treatment of scorpion stings, and closely represents the natural course of scorpion envenoming. The majority of cases $(95 \%)$ were not treated in hospital. First aid was the most commonly used treatment, including ice packs and topical treatments. There was variable response to these, but none completely relieved the pain. There was a poor response in 20 patients $(21 \%)$ who received analgesia. This may have been because the majority received oral paracetamol only.

Our study had a number of limitations. The first was the bias created by the recruitment of patients, in that they had to have caught the scorpion and then be willing to send it to the investigators. This requirement is likely to have biased the stings reported in environments of good lighting and unnatural backgrounds, as most scorpions (especially Lychas and Cercophonius spp.) are well camouflaged on natural surfaces. Sting events occurring outdoors and/or during the evening would be less likely to capture the responsible organism and thus excluded from the study. Another challenge confronted in this study is the current state of scorpion taxonomy in Australia, particularly for Lychas and Urodacus species. Observations were limited to the resolution of stings from different genera and families. Species level analysis of the stings reported in this study is currently impossible with clearly different species frequently keying to the same species using the current taxonomy and identification tools (Koch, 1997; Kovarik, 1997).

Australian health care workers should be aware that scorpions do occur in Australia, but that they do not cause major envenoming. Severe localised pain may occur for a number of hours after the sting but patients can be reassured that there is unlikely to be any other effect. Most stings occur from the small buthid scorpions, the majority after dark and indoors. The small buthid scorpions also caused more severe effects than the larger Urodachus spp. The features of Australian scorpion stings may be similar to some other parts of the world and well designed prospective studies of definite stings with confirmed identification in other regions would improve our knowledge of scorpion stings and envenoming.

\section{Acknowledgements}

We would like to acknowledge the large number of people that have made this study possible, including the poison information specialists from NSW and WA poison information centres, and the nursing staff and doctors in many emergency departments around Australia, particularly Royal Darwin Hospital, who assisted in recruiting cases. Particular thanks to Bart Currie who made it possible to organise the study and Tony Smith for reading and critically commenting on the manuscript.

\section{References}

Abroug, F., Elatrous, S., Nouira, S., Haguiga, H., Touzi, N., Bouchoucha, S., 1999. Serotherapy in scorpion envenomation: a randomised controlled trial. Lancet (354), 906-909.

Acosta, L.E., 1990. El genero Cercophonius Peters, 1861 (Scorpiones, Bothriuridae). Boletin de la Sociedad de Biologia de Concepcion (61), 7-27.

Bergman, N.J., 1997. Clinical description of Parabuthus transvaalicus scorpionism in Zimbabwe. Toxicon 35, 759-771.

Dehesa-Davila, M., Possani, L.D., 1994. Scorpionism and serotherapy in Mexico. Toxicon (32), 1015-1018.

Flecker, H., 1937. Injuries caused by Australian scorpions. Med. J. Aust. i, 875-876.

Freire-Maia, L., Campos, J.A., Amaral, C.F., 1994. Approaches to the treatment of scorpion envenoming. Toxicon (32), 1009-1014.

Ghalim, N., El-Hafny, B., Sebti, F., Heikel, J., Lazar, N., Moustanir, R., Benslimane, A., 2000. Scorpion envenomation and serotherapy in Morocco. Am. J. Trop. Med. Hyg. (62), 277-283.

Gibly, R., Williams, M., Walter, F.G., McNally, J., Conroy, C., Berg, R.A., 1999. Continuous intravenous midazolam infusion for Centruroides exilicauda scorpion envenomation. Ann. Emerg. Med. (34), 620-625.

Groshong, T.D., 1993. Scorpion envenomation in eastern Saudi Arabia. Ann. Emerg. Med. (22), 1431-1437.

Isbister, G.K., 2002. Data collection in clinical toxinology: debunking myths and developing diagnostic algorithms. J. Toxicol. Clin. Toxicol. (40), 231-237.

Isbister, G.K., Gray, M.R., 2002. A prospective study of 750 definite spider bites, with expert spider identification. QJM (95), $723-731$ 
Ismail, M., 1994. The treatment of the scorpion envenoming syndrome: the Saudi experience with serotherapy. Toxicon (32), 1019-1026.

Koch, L.E., 1997. The taxonomy, geographic distribution and evolutionary radiation of Australo-papuan scorpions. Rec. West. Aust. Mus. (5), 83-367.

Kovarik, F., 1997. Revision of the genera Lychas and Hemilychas, with descriptions of six new species (Scorpiones: Buthidae). Acta Societ. Zoolog. Bohem. (61), 311-371.

Krifi, M.N., Kharrat, H., Zghal, K., Abdouli, M., Abroug, F., Bouchoucha, S., Dellagi, K., El Ayeb, M., 1998. Development of an ELISA for the detection of scorpion venoms in sera of humans envenomed by Androctonus australis garzonii (Aag) and Buthus occitanus tunetanus (Bot): correlation with clinical severity of envenoming in Tunisia. Toxicon (36), 887-900.

LoVecchio, F., Welch, S., Klemens, J., Curry, S.C., Thomas, R., 1999. Incidence of immediate and delayed hypersensitivity to Centruroides antivenom. Ann. Emerg. Med. (34), 615-619.

Luca, S.M., Meier, J., 1995. Biology and distribution of scorpions of medical importance. In: Meier, J., White, J. (Eds.), Clinical
Toxicology of Animal Venoms and Poisons, 1. CRC Press, Boca Raton, pp. 205-219.

MacGillivray, P.H., 1866a. On a case of death from pyaemia following the sting of a scorpion. Aust. Med. J. XI, 97-99.

MacGillivray, P.H., 1866b. On a case where death was probably caused by the sting of a scorpion. Aust. Med. J. XI, $129-131$.

Southcott, R.V., 1976. Arachnidism and allied syndromes in the Australian region. Rec. Adelaide Child. Hosp. (1), 97-186.

Southcott, R.V., 1986. Some harmful Australian arthropods. Scorpions, mites, ticks and myriapods. Med. J. Aust. 2 (145), 590-595.

Sutherland, S.K., Tibballs, J., 2001. Venomous arthropods of medical importance, other than spider and ticks. In: Sutherland, S.K., Tibballs, J. (Eds.), Australian Animal Toxins, Oxford University Press, Melbourne, pp. 489-533.

Wax, P., 2002. Features and management of scorpion (Centruroides exilicauda) envenomations in the American southwest. J. Toxicol. Clin. Toxicol. 40, 379-380. Abstract. 